\title{
REGULARIDADES DA VIDA: PERIÓDICOS ENQUANTO TEMAS DE PESQUISAS HISTÓRICO-ACADÊMICAS NO RIO GRANDE DO SUL
}

\author{
REGULARITIES OF LIFE: PERIODIC PRESS AS THEME OF \\ HISTORICAL-ACADEMIC RESEARCH IN RIO GRANDE DO SUL
}

\author{
Cláudio Kuczkowski ${ }^{31}$ \\ Tatiane Dumerqui Kuczkowski ${ }^{32}$
}

RESUMO: O texto reflete sobre a condição dos periódicos, enquanto objetos e documentos de pesquisa, no espaço da escrita acadêmica em História. Especificamente, examina a matéria nas teses defendidas nos Cursos de Doutorado dos Programas de Pós-Graduação de três Universidades do Rio Grande do Sul, Brasil: Pontifícia Universidade Católica do Rio Grande do Sul (PUCRS), Universidade Federal do Rio Grande do Sul (UFRGS) e Universidade do Vale do Rio dos Sinos (UNISINOS). O conjunto é composto por dezoito teses. As balizas cronológicas: a criação do primeiro desses cursos na PUCRS (1986) e o ano de 2016, marco comemorativo dos trinta anos de existência do primeiro curso, interstício também das outras duas experiências. A contribuição propóe-se constituir uma visão panorâmica de como esses materiais vêm sendo estudados. Nas leituras comparativas percebe-se a concentração dos estudos em áreas temáticas específicas, além da centralidade em determinados aspectos analíticos, teóricos e metodológico.

Palavras-Chave: Periódicos, Objetos de Pesquisa, Teses em História.

ABSTRACT: The text reflects on the condition of periodic press, as objects and research documents, in the space of academic writing in History. Specifically, it examines the subject in the doctoral theses defended in the Doctorate Courses of the Postgraduate Programs of three Universities of Rio Grande do Sul, Brazil: Pontifical Catholic University of Rio Grande do Sul (PUCRS), Federal University of Rio Grande do Sul (UFRGS) and University of the Sinos River Valley (UNISINOS). The set consists of eighteen theses. The chronological frameworks: the creation of the first of these courses at PUCRS (1986) and the year 2016, commemorating the thirty years of existence of the first course, also interspersed with the other two experiences. The contribution proposes to provide an overview of how these materials are being studied. In comparative readings we can see the concentration of studies in specific thematic areas, besides the centrality in certain analytical, theoretical and methodological aspects.

31 Professor de Ciências Sociais no Instituto Federal de Educação, Ciência e Tecnologia do Rio Grande do Sul (IFRS) - Campus Caxias do Sul - Doutorando no PPG em História - Universidade Federal de Santa Maria (UFSM). Área de concentração História, Poder e Cultura. E-mail: claudiokuczkowski@yahoo.com.br.

32 Técnica Administrativa no Instituto Federal de Educação, Ciência e Tecnologia do Rio Grande do Sul (IFRS) - Reitoria Bento Gonçalves - Mestranda PPG em Diversidade Cultural e Inclusáo Social - Federaçáo de Estabelecimentos de Ensino Superior Novo Hamburgo (Centro Universitário FEEVALE). Área de concentração Diversidade e Inclusão. E-mail: tatiane.kuczkowski@ifrs.edu.br 
Keywords: Doctoral Theses in History, Periodic Press, Sources and Research Objects.

\begin{abstract}
Uma descoberta que se confirma em diversas pesquisas dos últimos anos é que a imprensa, o rádio e a televisão contribuem para reproduzir, mais do que para alterar, a ordem social. Seus discursos têm função de mimese, de cumplicidade com as estruturas socioeconômicas e com os lugares comuns da cultura política. Mesmo quando registram manifestaçôes de protesto e testemunham a desigualdade, editam as vozes dissidentes ou excluídas de maneira a preservar o status quo. (CANCLINI, 2002, p. 50).
\end{abstract}

\title{
INTRODUÇÃO
}

Os periódicos são encontrados nas pesquisas históricas majoritariamente na condição de fontes. A utilizaçáo de meios da imprensa como fonte de pesquisa não é novidade em trabalhos acadêmicos, conforme pode ser constatado em uma simples consulta ao Banco de Teses e Dissertaçóes da Comissão de Aperfeiçoamento de Pessoal de Nível Superior (CAPES). A mesma inclinação é perceptível em relação à criação de linhas de pesquisa em diferentes Programas de Pós-Graduação, projetos de pesquisa e ao surgimento de espaços de publicação especializados.

As investigaçóes históricas realizadas no Brasil, pelo menos desde a década de 1970, confirmam o dado. Autores como Nelson Werneck Sodré (1983), Maria Helena Rolim Capelato (1988), Tania Regina de Luca (2005) e Ana Luiza Martins - em coautoria com a anterior (2008) reforçam a tendência ao mesmo tempo em que compóem o referencial inicial a muitos dos estudos posteriores às suas publicaçóes. Sem a pretensão de retomada da relação entre imprensa e história, de seus respectivos aparatos epistemológicos, aliás, ambos bem referenciados ${ }^{33}$, propomos uma leitura particular de um conjunto de teses, aqui na posição de documentos históricos, a fim de percebermos tangivelmente as orientaçốes estruturais que tais investigaçôes vem recebendo.

Em que pese o pioneirismo dos autores mencionados, o esforço por historicizar a imprensa e as relevantes críticas efetuadas no âmbito da historiografia em torno do tema, afinal são quarenta anos de esforços em qualificar essa documentaçáo historiograficamente, o enfoque ora apresentado é outro: examina-se a temática do periodismo sob o olhar de um grupo particular de investigaçóes, a constar, dezenove teses defendidas nos Cursos de Doutorado dos Programas de Pós-Graduação de três Universidades do Rio Grande do Sul, Brasil: Pontifícia Universidade Católica do Rio Grande do Sul (PUCRS), Universidade Federal do Rio Grande do Sul (UFRGS) e Universidade do Vale do Rio dos Sinos (UNISINOS), dedicadas à matéria. As pesquisas são oriundas do recorte temporal dos trinta anos transcorridos entre a criação do primeiro curso de doutorado na PUCRS (1986) e o marco

33 O texto de Tania Regina De Luca, "História dos, nos e por meio dos periódicos" (PINSKY, 2005, pp. 111-153, especialmente pp. 141-142) chega a listar "sugestôes práticas" e "dicas" gerais de orientação a quem se interesse por iniciar pesquisas nesse campo. Além dos autores já mencionados, para uma leitura crítica e específica sobre jornais, consultar: ELMIR, Cláudio Pereira. As armadilhas do jornal: algumas consideraçóes metodológicas de seu uso para a pesquisa histórica. Cadernos de Estudo n. 13, do PPG em História da UFRGS. Porto Alegre, dezembro de 1995, pp. 19-29. 
comemorativo dessas três décadas de existência (2016), cujo interstício recepciona a criação de doutorados em história nas outras duas instituiçôes (UFRGS, 1995; UNISINOS, 1999).

$\mathrm{Na}$ presente reflexão, periódicos - jornais ou revistas impressas de circulação diária, semanal, quinzenal, mensal ou mesmo semestral - —, para além do estatuto de fonte, são tratados enquanto partes integrantes, essenciais, dos temas investigados. A justificativa encontra-se na impossibilidade de separação de qualquer um dos objetos dos respectivos periódicos em estudo, sem que, com isso, sejam desfiguradas as propostas temáticas originais. Os periódicos são o alicerce de cada objeto estudado. ${ }^{34}$ Trata-se do exame das teses produzidas nos Programas de Pós-Graduação em História do Rio Grande do Sul com foco na imprensa periódica e que, mais do que documentos, são considerados condiçáo sine qua non à existência do próprio objeto de pesquisa.

Os próprios títulos das teses, tomados aleatoriamente, auxiliam na identificação dos trabalhos no sentido de existir certo grau de dependência no interior dos objetos de estudo entre os conteúdos de pesquisa e os periódicos, promovendo estes últimos para além da condição única de fontes. Veja-se os exemplos: "O Discurso Político-Partidário Sul-Rio-Grandense sob o prisma da imprensa rio-grandina (1868-1895)" (1998), "Imprensa Integralista, Imprensa Militante (1932-1937)" (2009) e "Prisioneiros da História. Trajetórias intelectuais na imprensa negra meridional' (2011). Mudam-se os escopos espaciais e temporais, as perspectivas, as metodologias, os interesses, mantém-se a unicidade objetiva evento-periódico.

O argumento central sustentado na discussão é o de que os periódicos possuem uma dupla funcionalidade epistemológica em relação às pesquisas que os exploram: por um lado, como objetos a serem investigados, propiciam a própria historicização, por representarem características particulares a determinados espaços e tempos e, por outro, geram relativa dependência dos inquiridores pelo expediente de regramento social em que foram constituídos. Há uma problemática escolhida para as pesquisas, no entanto, as categorias de análise que propiciam a resposta ao problema proposto são oriundas, na maioria das vezes, dos próprios periódicos estudados.

Dessa forma, o exame apresentado pretende contribuir no sentido de elucidar em que medida as respostas fornecidas aos problemas de pesquisa são condicionadas às estruturantes cedidas pelo objeto, de onde, a indicação de intrincamento entre este e o estado de fonte a que é submetido - implicado no esforço de regulação incurso nos periódicos.

\section{Periódicos e Teses em História no Rio Grande do Sul}

O total de teses defendidas nas três universidades (PUCRS, UFRGS e UNISINOS), entre 1986 e 2016, é de 435. Desse montante, vinte e quatro trabalhos podem ser acomodados na presente tipologia (aproximadamente 5,5\% do total). Destas, no entanto, nos apropriamos de dezenove (Quadro 1). Os cinco textos completantes (Quadro 2) estão sendo analisados em outro trabalho acadêmico. A justificação do recorte está no fato de estas serem as únicas instituições que contam, no período analisado, com um quadro de teses capaz de

34 A classificação das teses em tal condição independe da autoidentificação dos autores com a proposição, apenas atendendo a finalidades didáticas do delineamento ora desenvolvido. 
avaliação. ${ }^{35}$ A partir da consulta geral, constatou-se haver, com esse qualificativo, dezessete trabalhos defendidos na PUCRS, um na UNISINOS e um na UFRGS.

Quadro 1 - Lista das teses/fontes examinadas no presente texto.

ALVES, Francisco das Neves. O Discurso Político-Partidário Sul-Rio-Grandense sob o prisma da imprensa rio-grandina (1868-1895). 1998. Tese (Doutorado em História)Pontifícia Universidade Católica do Rio Grande do Sul, Porto Alegre, 1998. 3 v.

OLIVEIRA, Rodrigo Santos de. Imprensa Integralista, Imprensa Militante (1932-1937). 2009. 388 f. Tese (Doutorado em História) Pontifícia Universidade Católica do Rio Grande do Sul, Porto Alegre, 2009.

SANTOS, José Antônio dos. Prisioneiros da História. Trajetórias intelectuais na imprensa negra meridional. 2011. 281 f. Tese (Doutorado em História) Pontifícia Universidade Católica do Rio Grande do Sul, Porto Alegre, 2011.

MEYRER, Marlise Regina. Representaçóes do desenvolvimento nas fotorreportagens da Revista O Cruzeiro (1955-1957). 2008. 257 f. Tese (Doutorado em História) Pontifícia Universidade Católica do Rio Grande do Sul, Porto Alegre, 2008.

RIBEIRO, Marilene da Cunha. A construção do imaginário da mulher brasileira na fronteira oeste do Rio Grande do Sul: o que revelam os jornais do período de 1890 a 1910. 2008. 138 f. Tese (Doutorado em História) Pontifícia Universidade Católica do Rio Grande do Sul, Porto Alegre, 2008.

SENNA, Adriana Kivanski de. As tentativas de implantação do divórcio absoluto no Brasil e a Imprensa Rio-Grandina (1889-1916). 2006. 290 f. Tese (Doutorado em História) Pontifícia Universidade Católica do Rio Grande do Sul, Porto Alegre, 2006.

SILVEIRA, Caren Santos da. A construção do sujeito representativo da oposição liberal nas páginas da revista Veja (1979-1988). 2010. 359 f. Tese (Doutorado em História) Pontifícia Universidade Católica do Rio Grande do Sul, Porto Alegre, 2010.

MARTINS, Luis Carlos dos Passos. A grande imprensa "liberal” da Capital Federal (RJ) e a política econômica do segundo governo de Vargas (1951 - 1954): conflito entre projetos de desenvolvimento nacional. 2010. 362 f. Tese (Doutorado em História) Pontifícia Universidade Católica do Rio Grande do Sul, Porto Alegre, 2010.

GONÇALVES, Dilza Pôrto. A Instrução Pública, a Educação da Mulher e a Formação de Professores nos Jornais Partidários de Porto Alegre/RS (1869-1937). 2013. 307 f. Tese (Doutorado em História) Pontifícia Universidade Católica do Rio Grande do Sul, Porto Alegre, 2013.

35 A Universidade de Passo Fundo (UPF) e a Universidade Federal de Santa Maria (UFSM) iniciaram seus cursos de doutorado em História em 2014 e 2015 respectivamente, porém ainda não dispunham de um quadro de teses defendidas no período em exame. 
NASCIMENTO, Fernanda de Santos. A Imprensa Periódica Militar no Século XIX: Política e Modernizaçáo no Exército Brasileiro (1850-1881). 2015. 473 f. Tese (Doutorado em História) - Pontifícia Universidade Católica do Rio Grande do Sul, Porto Alegre, 2015.

NOGUEIRA, Maristel Pereira. O anticomunismo nos jornais: Correio do Povo, Diário de Notícias e Última Hora, uma perspectiva de análise. 2009. 298 f. Tese (Doutorado em História) Pontifícia Universidade Católica do Rio Grande do Sul, Porto Alegre, 2009.

SZATKOSKI, Elenice. O Jornal Panfleto e a construção do brizolismo. 2008. 191 f. Tese (Doutorado em História) Pontifícia Universidade Católica do Rio Grande do Sul, Porto Alegre, 2008.

DIAS, José Roberto de Lima. Percursos da racionalização do sagrado no espiritismo: um conjunto de ideias presentes na literatura e na imprensa brasileira (1857-1915). 2011. 273 f. Tese (Doutorado em História) Pontifícia Universidade Católica do Rio Grande do Sul, Porto Alegre, 2011.

SELBACH, Jeferson Francisco. Muito além da Praça de José Bonifácio: as elites e os “outsiders' em Cachoeira do Sul pela voz do Jornal do Povo. 2007. 395 f. Tese (Doutorado em História) Universidade do Vale do Rio dos Sinos, São Leopoldo, 2007.

SOSA, Derocina Alves Campos. História política do Brasil (1930-1946), sob a ótica da imprensa gaúcha. 2005. 203 f. Tese (Doutorado em História) Pontifícia Universidade Católica do Rio Grande do Sul, Porto Alegre, 2005.

BAMMANN, Kellen. Por trás de uma tampinha de Coca-Cola, um mundo de coisas boas: o American Way of Life nas Páginas de o Cruzeiro e Manchete (1950-1959). 2016. 202 f. Tese (Doutorado em História) Pontifícia Universidade Católica do Rio Grande do Sul, Porto Alegre, 2016.

GOMES, Carla Renata Antunes de Souza. Entre tinteiros e bagadus: memórias de sangue e tinta. A escrita da História em periódicos literários Porto-Alegrenses do século XIX (1856-1879). 2012. 349 f. Tese (Doutorado em História) Universidade Federal do Rio Grande do Sul, Porto Alegre, 2012.

NUNES, José Luiz Martins. Censura e Imprensa no Estado Novo: os articulistas do Correio do Povo. 2002. 273 f. Tese (Doutorado em História) Pontifícia Universidade Católica do Rio Grande do Sul, Porto Alegre, 2002.

SCHERER JUNIOR, Charles. A Revista Selecciones del Reader's Digest e a constituição dos estereótipos do american way of life: 1940/1950. 2009. 208 f. Tese (Doutorado em História) Pontifícia Universidade Católica do Rio Grande do Sul, Porto Alegre, 2009.

Fonte: O autor, a partir dos dados disponíveis nos Programas de Pós-Graduação em História do Rio Grande do Sul e no Banco de Teses \& Dissertações - CAPES. Acesso em: 31 dez. 2017. 
Quadro 2 - Lista das teses/fontes examinadas excluídas da presente análise.

COUTO, Cristiano Pinheiro de Paula. Intelectuais e exílios confronto de resistências em revistas culturais: encontros com a civilização brasileira, Cuadernos de Marcha e Controversía (1978-1984). 2013. 243 f. Tese (Doutorado em História) Universidade Federal do Rio Grande do Sul, Porto Alegre, 2013.

NASCIMENTO, Jorge Luiz do. Trincheiras ideológicas: o debate entre os jornais peruanos El Comercio e La Tribuna. 2010.314 f. Tese (Doutorado em História) Universidade Federal do Rio Grande do Sul, Porto Alegre, 2010.

BETT, Ianko. Catolicismo e Cruzada. Revistas católicas e o imaginário anticomunista no Brasil e Argentina (1960 - 1967). 2015. 409 f. Tese (Doutorado em História) Pontifícia Universidade Católica do Rio Grande do Sul, Porto Alegre, 2015.

DALMÁZ, Mateus. Democracia e Concerto Americano: a visão de O Cruzeiro sobre a Argentina nas relações interamericanas (1946-1966). 2014. 167 f. Tese (Doutorado em História) Pontifícia Universidade Católica do Rio Grande do Sul, Porto Alegre, 2014.

ANTONI, Edson. O Discurso Jornalístico e o Processo de Marginalização Social do Exército Zapatista de Libertação Nacional e do Movimento dos Trabalhadores Rurais Sem Terra. 2012. 172 f. Tese (Doutorado em História) Pontifícia Universidade Católica do Rio Grande do Sul, Porto Alegre, 2012.

Fonte: O autor, a partir dos dados disponíveis nos Programas de Pós-Graduação em História do Rio Grande do Sul e no Banco de Teses \& Dissertações - CAPES. Acesso em: 31 dez. 2017.

Os orientadores e respectivos anos de conclusão foram Braz Augusto Aquino Brancato (1998), Moacyr Flores (2002, 2008), Earle Diniz Macarthy Moreira (2005), Sandra Maria Lubisco Brancato (2006, 2008, 2009), Helder V. Gordim da Silveira (2008, 2009, 2010), Cláudia Musa Fay (2009, 2010), Charles Monteiro (2011), Maria Lúcia Bastos Kern (2011), Maria Helena Camara Bastos (2013), René Ernaini Gertz (2015) e Jurandir Malerba (2016). Na Tese defendida junto à UNISINOS a orientação esteve sob a responsabilidade de Eliane Cristina Deckmann Fleck (2007) e, na UFRGS, de Temístocles Américo Corrêa Cezar (2012). Desse quadro é possível inferir, em primeiro lugar, a polivalência dos orientadores em relação aos temas e a consonância dos mesmos com as linhas de pesquisa dos respectivos Programas; em segundo, a existência de interesses continuados em investigações dessa essência e, em terceiro, permite mapear, em certa medida, os grupos teóricos aos quais os estudos estáo vinculados, a partir dos lugares de seus orientadores.

Nas ocasióes em que o periodismo é tematizado, os quadros analíticos aparecem basicamente divididos em dois eixos: em um, examinam-se os aspectos externos ao respectivo objeto: tiragem, caráter de propriedade (público ou privado), possíveis influências políticas e/ou econômicas, público de destino, etc. No outro eixo, configuram-se as discriminantes internas ao periódico: espacialidade e condiçôes físicas ocupadas pelo texto, elementos semióticos, de sintaxe e concordância, características argumentativas de quem escreve e/ ou edita, entre outros. Em paralelo, e é o que há de habitual nas investigaçóes, independente da origem na História, na Biblioteconomia, nas diversas áreas da Comunicação ou 
Linguística, áreas em que predominam as discussóes sobre o periodismo, há uma preocupação em compreender as ideias postas em circulação em determinados momentos, a partir das condições efetivas e materiais de produção.

No âmbito desse conjunto de textos, cabe atentar para o fato de que as teses, neste momento elencadas, normalmente náo restringem suas consultas aos materiais dos meios de comunicação compositores centrais na investigação. No estudo dos periódicos, são motes recorrentes de observação, o contexto (espacialidade e temporalidade), os públicos leitores (noçóes de teoria da recepçáo), interesses envolvidos e concepçóes teóricas (desde o significado de um periódico até as funçôes de orientação a que esteja propenso). Da mesma maneira, não se descuidam as formas técnicas de apresentação, singulares pelo caráter estético que ocupam. O trato com os periódicos ocasiona ainda outros destaques, a exemplo da forte presença metodológica da análise de conteúdo e do enfoque predominantemente político entre as matérias das pesquisas.

No que tange a análise de conteúdo - na maior parte das vezes fundamentada em Laurence Bardin ${ }^{36}$ — a mençáo reitera-se em, Marlise Regina Meyrer (2008, p. 25), Marilene da Cunha Ribeiro (2008, p. 17), Rodrigo Santos de Oliveira (2009, p. 19), Adriana Kivanski de Senna (2006, p. 16), Caren Santos da Silveira (2010, p. 20), Luis Carlos dos Passos Martins (2010, p. 13), Dilza Pôrto Gonçalves (2013, p. 22) e Fernanda de Santos Nascimento (2015, p. 25). Em alguns casos a noção percorre toda a tese, em outros, somente um capítulo. Noutros ainda pode ser utilizada parcialmente, conforme ocorre em Maristel Pereira Nogueira ao servir-se particularmente da concepção de "Leitura Flutuante" (2009, p. 12).

Nesse quesito, a base no passado e escrita das fontes, inibe a geração de uma identidade imediata entre o que foi escrito/publicado e aquilo que teria sido a intençáo das respectivas autorias. A afinidade torna-se mediada pelo tipo documental a que se tem acesso, no caso, os impressos. À linguagem resta a interposição, de onde as interpretações, cujo suporte metodológico advém de áreas múltiplas, com estatutos de disciplina próprios, a exemplo da linguística, para o caso de estudos textuais, da filosofia e correlatas implicaçóes hermenêuticas e da ciência política, quando a problemática envolver relaçóes de poder, ideologias, posições partidárias, etc.

O componente político está presente na grande maioria dos objetos. Francisco das Neves Alves, por exemplo, sustenta - sobre a relação entre imprensa e política:

Em se tratando de pesquisas abordando a história política, o papel da imprensa avulta em importância, tendo em vista o caráter em geral lacônico que caracteriza muitos dos documentos

36 Na resposta à própria pergunta "O que é a análise de conteúdo atualmente?” Bardin explicava, no prefácio à edição de sua obra: "Um conjunto de instrumentos metodológicos cada vez mais subtis em constante aperfeiçoamento, que se aplicam a 'discursos' (conteúdos e continentes) extremamente diversificados. O fator comum destas técnicas múltiplas e multiplicadas - desde o cálculo de frequências que fornece dados cifrados, até à extração de estruturas traduzíveis em modelos - é uma hermenêutica controlada, baseada na dedução: a inferência. Enquanto esforço de interpretação, a análise de conteúdo oscila entre os dois pólos do rigor da objetividade e da fecundidade da subjetividade. Absolve e cauciona o investigador por esta atracção pelo escondido, o latente, o não-aparente, o potencial de inédito (do não-dito), retido por qualquer mensagem.” (1979, p. 9). 
oficiais no que tange às disputas e aos confrontos de natureza político-partidária. Nos jornais, ao contrário, esses conflitos encontram seu espaço de propagação, chegando o jornalismo a servir como elo de ligação ou agente de combate entre diferentes tendências político-ideológicas (2002, p. 15).

Adriana Kivanski de Senna assevera categoricamente: "Politicamente cada um dos periódicos tinha a sua identidade partidária, apesar de se declararem, na virada de século, como órgãos apartidários." (2006, pp. 12-13). O exemplo se repete em Elenice Szatkoski ao tratar do objetivo de sua tese:

[...] entender o papel político do jornal que fomentou a construção do brizolismo, ideologia que tomou vulto no corpo social por apresentar à sociedade ideias já existentes anteriormente, bem como conceitos presentes e aceitos no varguismo trabalhista e populista. (2008, p. 10)

E poderia ser replicado tantas vezes quanto o número dos trabalhos aqui comentados. ${ }^{37}$

As opções em termos de fundamentação teórica predominantes nas teses variam entre a Nova História Política e a História Cultural, por vezes intermediadas pela História Social. No intervalo dessas concepçóes surgem algumas proposiçóes de maior especificidade como a Nova História Militar (NASCIMENTO, p. 2015) e a História das Ideias (DIAS, 2011 , p. 8). Para além das perspectivas enunciadas, de exames globais, multidisciplinares e de complexidades, denota-se a pertinência em grande medida, dos estudos revalidantes das clássicas divisóes entre campos históricos, ora renovados.

Os autores de suporte geral consubstanciam a ideia: evidenciam-se, René Rémond, Peter Burke, Roger Chartier, Pierre Bourdieu, Sandra Pesavento (na maioria das vezes ligada aos dois últimos), Roland Barthes e Edwar Palmer Thompson. Em menor intensidade, Walter Benjamin, Pierre Nora, Giovanni Levi, Carlo Ginzburg, Michel Foucault, Jean-Pierre Rioux, Marshall Berman e Norbert Elias.38 Por trás do conjunto de autores -base está a ideia da introdução de alguma mudança na "cultura historiográfica” (DIEHL, 1993; 1998; 1999; 2002). Parafraseando François Hartog (2014), configura-se, apesar das diferenças nas concepçóes que os orientam, um "regime de historicidade" característico a um tempo determinado, neste caso, marcado pela renovação percebida em uma historiografia (talvez sociologia, antropologia, filosofia...) relativamente recente.

37 José Antônio dos Santos considera que o simples ato de fundar jornais com uma definição étnico-racial explícita deva ser entendido como uma ação política. (2011, p. 20).

38 Jürgen Habermas, Milton Santos, Paulo César da Costa Gomes, Lucrécia D’Aléssio Ferrara, entre outros são citados em Jeferson Francisco Selbach (2007), respeitadas duas peculiaridades: ser a única Tese sobre o tema defendida fora da PUCRS e, também, o único autor advindo de fora da História (Licenciado em Ciências Sociais). Ressalte-se, no entanto, que isso não inibe o intercâmbio com outras áreas do conhecimento, como se confirma em José Antônio dos Santos. O autor apropria-se de alguns fundamentos sociológico para a realização de seu trabalho. Em seus termos: "O uso da metodologia de enfoque sociológico se mostrou bastante produtiva no resgate de trajetórias individuais e a sua composiçâo em redes de formação, interesses e sociabilidades. A intenção foi identificar características comuns — datas de nascimento e morte; casamento e família; formas de acesso a educação; fonte de riqueza pessoal; ocupação profissional; religiosidade; posicionamento político; circulação na sociedade e no meio negro; envolvimento com a comunidade de origem — dentre os principais responsáveis pela fundação e manutenção dos jornais." (2011, p. 20). 
Os períodos estudados não ultrapassam os séculos XIX e XX. A concentração ocorre em três momentos especialmente: o primeiro, a transição entre os dois séculos, o segundo, na década de 1930 e o terceiro nos anos 1950. Na mesma linha de outros tópicos temáticos constantes no rol total das teses, há leve tendência à estudos voltados ao Rio Grande do Sul ou partes deste, como bem o ilustra Carla Renata Antunes de Souza (2012). A forma de abordar a interdependência imprensa-história é o que muda relevantemente de um trabalho para outro. Em Derocina Alves Campos Sosa (2005) encontra-se um capítulo dedicado especificamente para tal finalidade. O texto apresenta a seguinte estrutura: 1.1 - Os discursos construídos pelos jornais; 1.2 - Os discursos manipulados nos jornais; 1.3 - As relaçóes da imprensa escrita com o poder e, 1.4 - A imprensa gaúcha e seus limites discursivos nas décadas de 1930 e 1940, de onde a evidência da preocupaçáo com a posição teórica em torno do tema. Já, em Rodrigo Santos de Oliveira (2009) os subsídios tendem aos aspectos relativos à História Política em detrimento da imprensa em si.

Uma vez mais, os objetos-fonte instruem (tendem a direcionar) espacial e temporalmente as teses. Dito de outra forma, o acesso às fontes, a disponibilidade das mesmas ou até a existência de periódicos no Brasil em períodos históricos específicos conduzem aos dois séculos em questão. Na mesma linha, a existência de espaços de pesquisa beneficia e/ ou facilita os trabalhos de investigação. Tania Regina De Luca, em meio a alguns alertas, informa haverem acervos de periódicos distribuídos por todo o país: "Universidades, museus, Institutos Históricos, centros de documentação, instituiçóes de pesquisa, bibliotecas e arquivos, públicos ou privados, além das próprias empresas jornalísticas, abrigarem coleçóes significativas de periódicos” (2005, p. 142). Restaria saber se a escolha dos temas pelos autores das teses, em que pese o caráter subjetivo da medida, guiou-se por tais elementos.

A noção de ideologia perpassa algumas dessas Teses. Modelar nesse sentido é o trabalho de Caren Santos da Silveira. ${ }^{39}$ A autora baseia as discussóes em torno de Antonio Gramsci e seu conceito de ideologia enquanto "uma concepção do mundo que se manifesta implicitamente na arte, no direito, na atividade econômica, em todas as manifestaçôes da vida individual e coletiva" (GRAMSCI, 2001, apud SILVEIRA, 2010, p. 32), e, a partir daí, desenvolve a narrativa utilizando-se dessa ideia por dezenas de vezes no texto. No mesmo viés, Dilza Pôrto Gonçalves, ao analisar "como os jornais partidários noticiavam os assuntos relacionados à Instrução Pública, à educação da mulher e à Escola Normal/ Colégio Distrital/Escola Complementar/Escola Normal/Escola Normal General Flores da Cunha, em Porto Alegre (1869-1937)?” e, ainda, “como, esses discursos partidários influenciaram na construção de uma imagem/representação de 'escola modelo' para essa instituição?" (2013, p. 19) questionará: "Qual a história desses periódicos? Onde ou quando as histórias dos periódicos se cruzavam com a Escola? Quem eram os redatores desses periódicos? A que grupo social pertenciam? Quais discursos ideológicos eram defendidos?” (2013, p. 20).

39 No mesmo sentido consultar Maristel Pereira Nogueira (2009). A autora trabalha o conceito de ideologia apoiada em Marilena de Souza Chaui e, ainda, Luis Carlos dos Passos Martins, onde a referência ao componente ideológico advém de Pierre Bourdieu - Campo de Produção Ideológica (2009, 11). 
A partir dessas dúvidas, além da questão envolvendo os componentes ideológicos, uma outra problemática se manifesta, a constar, a dos elementos examinados internamente aos periódicos. Exploram-se desde a linguagem em relação à época de sua produção até as alternâncias e veemências das notícias nos espaços dos periódicos, sem desmerecer as estratégias de divulgação, os aparatos técnicos e mesmo os personagens envolvidos. Senna, explicando como sistematizara sua análise esclarece que, após classificar de forma primária os textos entre opinativos e informativos (referindo-se à divisão realizada por José Marques Melo), secundariamente "o texto foi analisado em relação ao seu texto narrativo. As unidades que compóem essa categoria foram sendo percebidas na leitura dos jornais e são: artigo, carta, comentário, crônica, editorial, entrevista, nota, notícia e resposta à carta” $(2006,20)$. Santos, no teor de seu objeto, precisa tal matéria:

Ao voltar ao escrutínio da fonte de pesquisa principal, - o tamanho, o formato, o tipo de papel, a qualidade da impressão, a divisão de conteúdos, os lugares de circulação, os nomes dos envolvidos, o público que visava atingir, os principais temas abordados -, dentre outros aspectos, forneceram subsídios para as leituras e interpretaçóes daquela realidade anunciada na imprensa negra. (2011, p. 16).

O expediente de leitura é reforçado por práticas atentas aos aspectos de fundo como é retratado por Sosa ao advertir:

[...] aquilo que aparece escrito deve ser lido em dois tempos: um objetivo que interpreta o que está escrito efetivamente e outro subjetivo que precisa entender o que não aparece escrito, mas é possível de identificar à luz do contexto histórico. (2005, pp. 7-8).

Os denotadores aparecem sempre em dois sentidos, um no que tange aos aspectos teóricos das próprias teses e outro no relativo às características pronunciadas em torno dos periódicos. Exemplificativa do primeiro caso é a passagem de Szatkoski:

Ao nos propormos um estudo do envolvimento da imprensa com um movimento político, realizamos uma revisão teórica de autores que fazem análises sobre a comunicação e a influência dos meios de comunicação nas questóes políticas, expondo alternativas a esta discussáo, que volta novamente no campo da historiografia, e traçando um panorama acerca do "político". $(2008,15)$.

Já, na segunda forma, Oliveira, considerado o fato de se tratar de investigação sobre a imprensa militante, acrescenta à imprensa integralista algumas funçóes tradicionalmente singulares, de certa forma exteriores ao conteúdo periodístico 40 propriamente dito:

A utilizaçẫo dos jornais e revistas garantia a difusão de uma mensagem a um custo relativamente baixo. O filiado não precisava ir a um núcleo para receber a sua carga doutrinária, ele podia comprar a um custo baixo em uma banca ou receber em sua residência, caso os assinasse. Desta forma, quem não era membro do integralismo podia ler o jornal ou a revista e aderir ao movimento. Ao mesmo tempo, um único exemplar tinha como ser consumido por mais de um indivíduo. Ou seja, a imprensa não era apenas um instrumento pedagógico, mas também uma ferramenta de cooptação social. (2009, p. 15).

40 Nesse sentido, Martins escreve: "Com base no conceito de campo jornalístico devemos entender que o universo dos jornais não é um espaço homogêneo e unificado e sim um espaço de luta, onde se dá uma série de conflitos entre agentes, ideias, programas e projetos que buscam legitimidade social." (2010, p. 12). 
Ademais, os trabalhos com periódicos denotam uma característica peculiar em relaçáo às fontes. Diferentemente da maioria das outras teses, nesse tópico é possível ler declaraçóes do tipo "Todos os periódicos consultados fazem parte do acervo da Hemeroteca da Biblioteca Nacional" (NASCIMENTO, 2015, p. 27) ou mesmo, "Todos os locais disponibilizaram prontamente seu acervo para a pesquisa." (SOSA, 2005, p. 11). Para além de serem incomuns, essas observações sinalizam espécies de documentos que ocupam posiçóes privilegiadas nos processos de escolhas para arquivamento. Fazem parte do que deve ou não ser preservado - e como seráo disponibilizados - nos acervos memorialísticos em um contexto e lugar determinado.

Os periódicos são apresentados nas teses como representantes, em sua grande maioria, de interesses de um grupo determinado, independentemente se de caráter elitista, partidário, associativo, estatal e/ou mesmo das vontades dos proprietários privados, patrocinadores ou leitores do órgáo de imprensa. Meyer alude, tratando da revista $O$ Cruzeiro:

[...] de um lado, no fato de ela exprimir os interesses de um grupo poderoso — o seu público leitor, composto pelas camadas altas e médias da sociedade, sensível às transformaçôes decorrentes do crescimento acelerado que vinha ocorrendo no último decênio - de outro, pelo prestígio que a revista desfrutava no campo jornalístico. (2008, pp. 16-17).

Na mesma linha, Selbach: "Neste contexto ideológico, algo que perpassou e sobreviveu as mudanças administrativas do Jornal do Povo foi o fato dos editores defenderem veementemente os ideais da elite." (2007, p. 85).

$\mathrm{O}$ entendimento de que os periódicos permitem a visualização das cenas cotidianas incide em diversas teses. Adriana Kivanski de Senna, após frisar a importância dos pesquisadores no conhecimento da "realidade" manifestada nos jornais, em sua contextualização e atribuição de pertinência às "suas falas", acredita que "a partir delas se possa conhecer $o$ pensamento de uma época, o seu cotidiano." (2006, 9). A expressão percorre ainda as teses: $O$ anticomunismo nos jornais: Correio do Povo, Diário de Notícias e Última Hora, uma perspectiva de análise (NOGUEIRA, 2009) e Por trás de uma tampinha de Coca-Cola, um mundo de coisas boas: o American Way of Life nas Páginas de o Cruzeiro e Manchete (1950-1959) (BAMMANN, 2016), esta chega a concluir que Folhear os semanários permite conhecer os planos econômicos, os enredos políticos e os anseios da sociedade brasileira. (2016, p. 13).

As categorias analíticas presentes nas teses variam conforme as temáticas, não advindo, portanto, de quaisquer modelos preconcebidos. Na tentativa de explicar "Por que a censura não se mostrou eficaz sobre o discurso dos articulistas do Correio do Povo?”, José Luiz Martins Nunes trabalha com as categorias Estado Novo e Segunda Guerra Mundial, partindo "de variáveis como nacionalismo, autoritarismo e democracia." (2002, 5). Da mesma forma, Senna organiza seu texto a contar das "unidades percebidas nos jornais: o lar e a família, a mulher, o fator religioso, notícias de outros jornais, o ponto de vista do jornal, a manifestação do leitor, o casamento, o divórcio e a moral e os costumes." (2008, 18). Maristel Pereira Nogueira avança no aclaramento de como atinge as "unidades constituintes" (2009, 19), ou seja, as categorizaçōes "Comunismo x Família", "Comunismo x Democracia", "Comunismo x Bem" e "Comunismo x Propriedade Privada" (2009, pp. 20), com as quais trabalha: 
Nossa leitura tem a interpretação que compreendemos como pesquisadores, assim como, também o leitor do jornal no período estudado tem sua própria leitura, conforme o contexto em que está inserido. O próximo passo é o estabelecimento de relações. É nesta etapa que podemos estabelecer as categorizações, ou seja, reunir elementos próximos resultando daí as categorias de análise. (2009, pp. 20).

A força do objeto-fonte manifesta-se na configuração das categorias. Para mais, o excerto contempla outra tendência nos trabalhos sobre periódicos: a propensão a uma espécie de leitura escalonada, ou seja, interpretar os textos analisados como resultados de pelo menos uma interpretação prévia da realidade. Marlise Regina Meyrer explanando em torno da figura de Assis Chateaubriand - figura recorrente em diversos trabalhos - reconhece-o como "homem de seu tempo, que vivenciou o contexto histórico nacional da época e fez a sua leitura sobre as questóes que estavam sendo discutidas então." (2008, 19). Daí concluir que, "a revista $O$ Cruzeiro, ao expressar o contexto nacional do período, passava, também, por essa leitura." (SENNA, 2008, p. 19). O mesmo se repete em Nogueira ao ressaltar a necessidade de "[...] sempre ter em mente que tudo que é produzido tem a subjetividade de quem o produz, neste caso, do jornalista que escreveu o texto e do historiador que o interpreta." (2009, p. 13).

No mais das vezes existe a ressalva nas investigaçóes de não ser o trabalho um esforço de compreensão da recepção e sim da emissão das mensagens emanadas dos periódicos. Charles Scherer Júnior sintetiza:

[...] não tencionamos perscrutar a questão de como eram recebidas as mensagens de Selecciones del Reader's Digest, mas, sim, de que forma o seu conteúdo discursivo e semântico expressava o imaginário dos norte-americanos em relação ao significado das ameaças externas e suas constantes re-significaçóes. (2009, p. 24).

A postura é reiterada também em Nogueira, quem considera a necessidade da realização de pesquisa específica com finalidade de trabalhar "a teoria da recepção". (2009, p. 27).

De todos os modos, os periódicos enquanto fonte e objeto de pesquisa, podem ser vistos como regularidades de vida, tanto no sentido de encontrarem-se submetidos a uma série de regras e limites quanto no que se refere às configurações que intentam criar aos seus contemporâneos. Efeitos da periodicidade, por vezes cambiante, são dispositivos de poder, capazes de elevação à condição de eventos caraterísticas cotidianas e conjuntos de ideias que poderiam passar despercebidas, não fosse a força de materialização, o recurso de espaços onde ordinariamente são construídas versóes da vida.

\section{CONSIDERAÇÕES FINAIS}

$\mathrm{Na}$ conjuntura de História e Imprensa a carga política nos periódicos é lida acauteladamente. Sob os auspícios de espaços de poder e manipulaçáo, do reconhecimento de tratar-se de uma realidade anunciada, advém a constatação de já comporem interpretaçóes prévias, de quem escreve, de quem leu à época, das leituras intermediadas. Contanto o 
detrimento da teoria da recepção em relação à produçáo, há preocupaçáo com as possibilidades de leitura e para quem é direcionada a escrita, à quais interesses servem as diferentes plataformas.

A forte presença da História Cultural nesse meio demonstra, em certa medida, os periódicos sendo vistos como discursos (linguagem e estrutura narrativa) simbólicos, representacionais, ou mesmo enquanto recursos estéticos, através dos efeitos de diagramação, por exemplo. Se, por um lado, a análise de conteúdo encontra atmosfera privilegiada, por outro, o exame de aspectos externos e de fundo (contextuais) permite considerar o quanto esses mecanismos fundacionais, lidos em seus ambientes, vem sopesando na constituição de novas espacialidades e temporalidades.

No que tange ao elemento político sobressalente nas pesquisas históricas relativas ao periodismo, a imprensa parece ocupar a posição de construção, limitaçáo, manipulação e propagação de ideias - adjetivaçóes recorrentes particularmente na relação imprensa-política. Isso nem sempre ocorre de forma direta. Em alguns casos, a posiçáa é de complementaçáo das fontes oficiais; em outros, servem de espaço de conflitos de ideias (apoio expresso de maneira explícita ou implícita). De uma ou outra formas, o intento está nos efeitos empíricos, na vida prática. Os resultados dessas construçôes se dão, intrinsecamente, no interior das diferentes sociedades, significando e ressignificando imaginários, configurando representaçóes.

Vale anotar, as pesquisas estão estruturadas, em grande medida, a partir daquilo que os próprios periódicos fornecem - categorias de análise e pressupostos. Relacionados ou não à disponibilidade de fontes, ocasionam-se, por vezes, riscos derivados do princípio de "estar tudo pronto", dos grandes achados arquivísticos. Em contrapartida, instiga-se os investigadores a desconfiarem das fontes pré-selecionadas, a inquirirem para além do que aparece em primeira instância, do imediato. Os periódicos ocupam a posição de mediaçáo no processo de objetivaçáo, auxiliam na delimitaçáo contextual (o antes e o depois) determinantes de eventos e estruturas, além de suas inter-relaçóes. Ou, como alertara Reinhart Koselleck, "[...] o controle assegura a exclusão daquilo que não deve ser dito. Mas esse mesmo controle não prescreve aquilo que pode ser dito.” (2006, p. 141). 


\section{REFERÊNCIAS}

ALVES, Francisco das Neves. O discurso político-partidário sul-rio-grandense sob o prisma da imprensa rio-grandina (1868-1895). Rio Grande: FURG, 2002.

. O Discurso Político-Partidário Sul-Rio-Grandense sob o prisma da imprensa rio-grandina (1868-1895). 1998. Tese (Doutorado em História) Pontifícia Universidade Católica do Rio Grande do Sul, Porto Alegre, 1998. 3 v.

ANTONI, Edson. O Discurso Jornalístico e o Processo de Marginalização Social do Exército Zapatista de Libertaçáo Nacional e do Movimento dos Trabalhadores Rurais Sem Terra. 2012. 172 f. Tese (Doutorado em História) Programa de Pós-Graduação em História, Pontifícia Universidade Católica do Rio Grande do Sul, Porto Alegre, 2012.

BAMMANN, Kellen. Por trás de uma tampinha de Coca-Cola, um mundo de coisas boas: o American Way of Life nas Páginas de o Cruzeiro e Manchete (1950-1959). 2016. 202 f. Tese (Doutorado em História) Programa de Pós-Graduação em História, Pontifícia Universidade Católica do Rio Grande do Sul, Porto Alegre, 2016.

BARDIN, Laurence. Análise de Conteúdo. Lisboa: 70, 1979.

BETT, Ianko. Catolicismo e Cruzada. Revistas católicas e o imaginário anticomunista no Brasil e Argentina (1960 - 1967). 2015. 409 f. Tese (Doutorado em História) Programa de Pós-Graduação em História, Pontifícia Universidade Católica do Rio Grande do Sul, Porto Alegre, 2015.

CANCLINI, Néstor García. Cidades e cidadãos imaginados pelos meios de Comunicação. OPINIÁO PÚBLICA, Campinas: Vol. VIII, no 1, 2002, pp. 40-53. Disponível em: <http:// www.scielo.br/pdf/op/v8n1/14873.pdf>. Acesso em: 26 set. 2017.

CAPELATO, Maria Helena Rolim. A imprensa na História do Brasil. São Paulo: Contexto/ EDUSP, 1988.

COUTO, Cristiano Pinheiro de Paula. Intelectuais e exílios confronto de resistências em revistas culturais: encontros com a civilização brasileira, Cuadernos de Marcha e Controversía (1978-1984). 2013. 243 f. Tese (Doutorado em História) Programa de PósGraduação em História, Universidade Federal do Rio Grande do Sul, Porto Alegre, 2013.

DALMÁZ, Mateus. Democracia e Concerto Americano: a visão de O Cruzeiro sobre a Argentina nas relaçóes interamericanas (1946-1966). 2014. 167 f. Tese (Doutorado em História) Programa de Pós-Graduação em História, Pontifícia Universidade Católica do Rio Grande do Sul, Porto Alegre, 2014.

DE LUCA, Tania Regina. História dos, nos e por meio dos periódicos. In: PINSKY, C. B. (Org.). Fontes Históricas. São Paulo: Contexto, 2005. pp. 111-153.

DIAS, José Roberto de Lima. Percursos da racionalização do sagrado no espiritismo: um conjunto de ideias presentes na literatura e na imprensa brasileira (1857-1915). 2011. 273 f. Tese (Doutorado em História), Pontifícia Universidade Católica do Rio Grande do Sul, Porto Alegre, 2011. 
DIEHL, Astor Antônio. A cultura historiográfica brasileira: década de 1930 aos anos 1970. EDIUPF, Passo Fundo: 1999.

A cultura historiográfica brasileira: do IHGB aos anos 1930. EDIUPF, Passo Fundo: 1998.

. A cultura historiográfica nos anos 80: mudança estrutural na matriz historiográfica brasileira - (IV). Porto Alegre: EVANGRAF, 1993.

SP: 2002.

Cultura historiográfica: Memória, identidade e representação. EdUSC, Bauru,

ELMIR, Cláudio Pereira. As armadilhas do jornal: algumas considerações metodológicas de seu uso para a pesquisa histórica. Cadernos de Estudo, Porto Alegre, n. 13, pp. 19-29, dez. 1995. (PPG em História da UFRGS)

GOMES, Carla Renata Antunes de Souza. Entre tinteiros e bagadus: memórias de sangue e tinta. A escrita da História em periódicos literários Porto-Alegrenses do século XIX (1856-1879). 2012. 349 f. Tese (Doutorado em História) Programa de Pós-Graduação em História, Universidade Federal do Rio Grande do Sul, Porto Alegre, 2012.

GONÇALVES, Dilza Pôrto. A Instrução Pública, a Educação da Mulher e a Formação de Professores nos Jornais Partidários de Porto Alegre/RS (1869-1937). 2013. 307 f. Tese (Doutorado em História) Programa de Pós-Graduação em História, Pontifícia Universidade Católica do Rio Grande do Sul, Porto Alegre, 2013.

HARTOG, François. Regimes de Historicidade: presentismo e experiências do tempo. Trad. de Andréa S. de Menezes, Bruna Breffart, Camila R. Moraes, Maria Cristina de A. Silva e Maria Helena Martins. Belo Horizonte: Autêntica, 2014.

KOSELLECK, Reinhart. Futuro Passado. Contribuição à semântica dos tempos históricos. Trad. Wilma Patrícia Maas e Carlos Almeida Pereira. Rio de Janeiro: Contraponto/ Ed.PUC-Rio, 2006.

MARTINS, A. L. \& DE LUCA, T. R. (Org.). História da Imprensa no Brasil. São Paulo: Contexto, 2008.

MARTINS, Luis Carlos dos Passos. A grande imprensa "liberal” da Capital Federal (RJ) e a política econômica do segundo governo de Vargas (1951 - 1954): conflito entre projetos de desenvolvimento nacional. 2010.362 f. Tese (Doutorado em História) Programa de Pós-Graduação em História, Pontifícia Universidade Católica do Rio Grande do Sul, Porto Alegre, 2010.

MEYRER, Marlise Regina. Representaçóes do desenvolvimento nas fotorreportagens da Revista O Cruzeiro (1955-1957). 2008. 257 f. Tese (Doutorado em História) Programa de Pós-Graduação em História, Pontifícia Universidade Católica do Rio Grande do Sul, Porto Alegre, 2008.

NASCIMENTO, Fernanda de Santos. A Imprensa Periódica Militar no Século XIX: Política e Modernização no Exército Brasileiro (1850-1881). 2015. 473 f. Tese (Doutorado 
em História) Programa de Pós-Graduação em História, Pontifícia Universidade Católica do Rio Grande do Sul, Porto Alegre, 2015.

NASCIMENTO, Jorge Luiz do. Trincheiras ideológicas: o debate entre os jornais peruanos El Comercio e La Tribuna. 2010.314 f. Tese (Doutorado em História) - Universidade Federal do Rio Grande do Sul, Porto Alegre, 2010.

NOGUEIRA, Maristel Pereira. O anticomunismo nos jornais: Correio do Povo, Diário de Notícias e Última Hora, uma perspectiva de análise. 2009. 298 f. Tese (Doutorado em História) Programa de Pós-Graduação em História, Pontifícia Universidade Católica do Rio Grande do Sul, Porto Alegre, 2009.

NUNES, José Luiz Martins. Censura e Imprensa no Estado Novo: os articulistas do Correio do Povo. 2002. 273 f. Tese (Doutorado em História) Programa de Pós-Graduação em História, Pontifícia Universidade Católica do Rio Grande do Sul, Porto Alegre, 2002.

OLIVEIRA, Rodrigo Santos de. Imprensa Integralista, Imprensa Militante (1932-1937). 2009. 388 f. Tese (Doutorado em História) Programa de Pós-Graduação em História, Pontifícia Universidade Católica do Rio Grande do Sul, Porto Alegre, 2009.

RIBEIRO, Marilene da Cunha. A construçáo do imaginário da mulher brasileira na fronteira oeste do Rio Grande do Sul: o que revelam os jornais do período de 1890 a 1910. 2008. 138 f. Tese (Doutorado em História) IPrograma de Pós-Graduação em História, Pontifícia Universidade Católica do Rio Grande do Sul, Porto Alegre, 2008.

SANTOS, José Antônio dos. Prisioneiros da História. Trajetórias intelectuais na imprensa negra meridional. 2011. 281 f. Tese (Doutorado em História) Programa de Pós-Graduaçáo em História, Pontifícia Universidade Católica do Rio Grande do Sul, Porto Alegre, 2011.

SCHERER JUNIOR, Charles. A Revista Selecciones del Reader's Digest e a constituiçáo dos estereótipos do american way of life: 1940/1950. 2009. 208 f. Tese (Doutorado em História) Programa de Pós-Graduação em História Pontifícia Universidade Católica do Rio Grande do Sul, Porto Alegre, 2009.

SELBACH, Jeferson Francisco. Muito além da Praça de José Bonifácio: as elites e os “outsiders' em Cachoeira do Sul pela voz do Jornal do Povo. 2007. 395 f. Tese (Doutorado em História) Programa de Pós-Graduação em História, Universidade do Vale do Rio dos Sinos, São Leopoldo, 2007.

SENNA, Adriana Kivanski de. As tentativas de implantaçáo do divórcio absoluto no Brasil e a Imprensa Rio-Grandina (1889-1916). 2006. 290 f. Tese (Doutorado em História) Programa de Pós-Graduação em História, Pontifícia Universidade Católica do Rio Grande do Sul, Porto Alegre, 2006.

SILVEIRA, Caren Santos da. A construçáo do sujeito representativo da oposiçáo liberal nas páginas da revista Veja (1979-1988). 2010. 359 f. Tese (Doutorado em História) Programa de Pós-Graduação em História, Pontifícia Universidade Católica do Rio Grande do Sul, Porto Alegre, 2010. 
SODRÉ, N. W. História da Imprensa no Brasil. São Paulo: Martins Fontes, 1983.

SOSA, Derocina Alves Campos. História política do Brasil (1930-1946), sob a ótica da imprensa gaúcha. 2005. 203 f. Tese (Doutorado em História) Programa de Pós-Graduaçáo em História, Pontifícia Universidade Católica do Rio Grande do Sul, Porto Alegre, 2005.

SZATKOSKI, Elenice. O Jornal Panfleto e a construçáo do brizolismo. 2008. 191 f. Tese (Doutorado em História) Programa de Pós-Graduaçáo em História, Pontifícia Universidade Católica do Rio Grande do Sul, Porto Alegre, 2008.

Artigo recebido em 12/10/2017 Artigo aceito em 19/01/2018 